\title{
Stomatin-like protein 2 is associated with the clinicopathological features of human papillary thyroid cancer and is regulated by TGF- $\beta$ in thyroid cancer cells
}

\author{
ZEBING LIU ${ }^{1-3^{*}}$, YU YANG $^{4 *}$, YOUYUAN ZHANG $^{1}$, XUANGUANG YE $^{1}$, LI WANG $^{1}$ and GUOXIONG XU ${ }^{3,5}$ \\ ${ }^{1}$ Department of Pathology, Jinshan Hospital, Fudan University, Shanghai 201508; ${ }^{2}$ Department of Pathology, \\ Fudan University Shanghai Cancer Center, Shanghai 200030; ${ }^{3}$ Department of Oncology, Shanghai Medical College, \\ Fudan University, Shanghai 200032; ${ }^{4}$ Shanghai Public Health Clinical Center, Fudan University, Shanghai 201508; \\ ${ }^{5}$ Central Laboratory, Jinshan Hospital, Fudan University, Shanghai 201508, P.R. China
}

Received September 25, 2013; Accepted October 28, 2013

DOI: $10.3892 /$ or.2013.2833

\begin{abstract}
Papillary thyroid cancer (PTC) accounts for 80-90\% of all cases of thyroid malignancies. Stomatin-like protein 2 (SLP-2) is a novel member of the stomatin superfamily and is found in several types of human tumors. However, whether it is expressed in human PTC is unknown. In the present study, we aimed to explore the diagnostic value of SLP-2 in patients with PTC and to investigate whether SLP-2 expression is regulated by transforming growth factor- $\beta$ (TGF- $\beta$ ), a cytokine which plays an important role in PTC tumorigenesis. A total of 107 patients consisting of 99 cases of classical and 8 cases of follicular variant PTC was examined. The expression of SLP-2 mRNA and protein was examined by immunohistochemistry (IHC) and qPCR, respectively. We found that SLP-2 was overexpressed in human PTC. The expression of SLP-2 was significantly associated with clinicopathological features of the PTC cases. Particularly, increased SLP-2 expression was mainly correlated with primary tumors $>1 \mathrm{~cm}$ in size, with late stage tumors and with metastatic lymph nodes. The expres-
\end{abstract}

Correspondence to: Professor Guoxiong Xu, Central Laboratory, Jinshan Hospital, Fudan University, 1508 Longhang Road, Shanghai 201508, P.R. China

E-mail: guoxiong.xu@fudan.edu.cn

Dr Youyuan Zhang, Department of Pathology, Jinshan Hospital, Fudan University, Shanghai 201508, P.R. China

E-mail: sszyys@163.com

*Contributed equally

Abbreviations: EMT, epithelial-mesenchymal transformation; IHC, immunohistochemistry; PDTC, poorly differentiated thyroid carcinoma; PTC, papillary thyroid cancer; qPCR, quantitative polymerase chain reaction; SI, staining index; SLP-2, stomatin-like protein 2 ; TGF- $\beta$, transforming growth factor $-\beta$

Key words: stomatin-like protein 2, thyroid cancer, proliferation, progression, TGF- $\beta$ sion of SLP-2 was correlated with the expression of Ki-67, a cell proliferation marker, in PTC tissues as detected by IHC. SLP-2 was upregulated by TGF- $\beta 1$ in PTC cells as evaluated by western blotting. The present data revealed for the first time that patients with PTC exhibited SLP-2 overexpression that was associated with clinicopathological features. The correlation between SLP-2 expression and proliferation marker Ki-67 may be characteristic of PTC and may reflect PTC progression. SLP- 2 was upregulated by TGF- $\beta 1$, indicating a possible role of SLP-2 in PTC tumorigenesis. Our data suggest that SLP-2 may be considered as a useful diagnostic marker and therapeutic target for PTC.

\section{Introduction}

The most common type of thyroid carcinoma, an endocrinerelated malignancy, is papillary thyroid cancer (PTC) that accounts for $80-90 \%$ of total cases (1). The incidence of thyroid cancer has been steadily increasing over the past 3 decades in many countries worldwide. Thyroid cancer has become the fifth leading type of cancer in women in the United States (2) and commonly occurs in younger individuals. However, the incidence rate of thyroid cancer has been increasing in all age groups since 1990 s. It is estimated that 60,220 individuals will be newly diagnosed with thyroid cancer and 1,850 deaths will result from thyroid cancer in the US in 2013 (2). Although the 5-year survival rate for patients with PTC, particularly in younger patients under 40 years of age, is quite favorable, the prognosis declines with each subsequent decade of life, such as in aged patients older than 60 years to a large degree. Despite the outright success of current therapies, $10-30 \%$ of patients with PTC develop recurrence and/or metastasis and eventually $\sim 6 \%$ of patients die from distant metastasis $(3,4)$. Currently, prognostic evaluation of PTC is based mainly on age, tumor size and clinical stage. However, the mechanisms underlying the association between clinicopathological features and molecular biology are not well understood. Recent studies have shown that a number of molecular markers of the primary tumor may serve as potent parameters with which to predict the clinical outcome of patients $(5,6)$. 
Human stomatin-like protein (SLP) is a member of the superfamily of stomatin proteins, including SLP-1, SLP-2 and SLP-3. SLP-2, also known as HSPC108, EPB72-like protein 2, was first cloned in 2000 and was identified as a novel plasma membrane-linked protein in erythrocytes (7); it is at present mainly considered as a mitochondrial inner membrane protein (8). The gene for human SLP-2, STOML2, is localized on chromosome 9p13 (9). Phylogenic analysis shows that SLP-2 is acquired through mitochondrial endosymbiosis and is widely distributed in most major kingdoms (10). Although it is now known to be expressed in a range of mammalian tissues and involved in the regulation of ion channel permeability, mechanoreception and lipid domain organization (7), the exact function and mechanisms are unclear. Recent studies have revealed that SLP-2 is required for stress-induced mitochondrial hyperfusion (11) and may be implicated in the interaction with prohibitins in the mitochondrial inner membrane, thereby contributing to mitochondrial stability and regulating their biogenesis and functions $(12,13)$.

SLP-2 was first identified as a novel cancer-related gene in 2006 and was found to be overexpressed in several types of human tumors, including breast cancer, gastric cancer, colorectal cancer, glioma, laryngeal squamous cell carcinoma (LSCC), esophageal squamous cell carcinoma (ESCC), lung cancer and endometrial adenocarcinoma (14-19). Inhibition of SLP-2 was found to decrease cell proliferation, adhesion and tumor cell motility (20), suggesting that SLP-2 may play an important role in tumorigenesis. A high level of SLP-2 has been associated with decreased survival of patients with breast cancer (17). A recent case study suggests that SLP-2 may be used as a biomarker for the early detection of colorectal cancer (18). However, expression of SLP-2 in thyroid cancer has not yet been explored. Furthermore, whether SLP-2 expression is regulated by cytokines that play important roles in PTC tumorigenesis is unknown. Transforming growth factor- $\beta$ (TGF- $\beta$ ) is one of the important cytokines involved in PTC development $(21,22)$. Changes in the expression of TGF- $\beta$ have been noted in the multistage development of thyroid cancer (23). Immunohistochemical (IHC) analysis detected TGF- $\beta 1$ in epithelial cells in 58\% of malignant thyroid tumors (including follicular, papillary and anaplastic variants), but was not noted in any of 7 benign tumors nor in any normal thyroid epithelium (23). Therefore, we speculated that an alteration in the expression of TGF- $\beta 1$ occurring specifically in PTC may regulate SLP-2 expression.

In the present study, we report for the first time that the expression of SLP-2 at the mRNA and protein levels is associated with the clinicopathological features of human PTC. Whether expression of SLP-2 is regulated by TGF- $\beta 1$ in thyroid cancer cells was also examined. Furthermore, we evaluated the correlation between SLP-2 expression and the proliferation index $\mathrm{Ki}-67$ and explored the diagnostic value of SLP-2 in patients with PTC.

\section{Materials and methods}

Patients and tissue preparation. A total of 107 patients diagnosed with PTC at Jinshan Hospital, Fudan University from August 2009 to September 2012, was examined. The study on human subjects was approved by the Ethics Committee of Jinshan Hospital, Fudan University. Among these cases confirmed by surgery and histopathology, 99 patients were diagnosed with classical PTC and 8 patients were diagnosed with follicular variant of PTC. The mean age of the patients was 46 years (range, 13-73 years) with a median age of 47 years. None of the patients had received radiotherapy or chemotherapy prior to surgery.

The $10 \%$ formalin-fixed paraffin-embedded samples were used for histological examination and were classified based on the tumor, node, metastasis (TNM) classification method from the American Joint Committee on Cancer (AJCC). In addition, freshly isolated primary tumor and adjacent normal thyroid tissues from the same cases were subjected to quantitative real-time PCR.

Immunohistochemical staining and scoring. Sections $(4 \mu \mathrm{m})$ were baked at $58^{\circ} \mathrm{C}$ for $2 \mathrm{~h}$ and then deparaffinized in xylene and hydrated with a series of graded alcohols. Antigen recovery was performed by heating the slides immersed in citrate buffer $(\mathrm{pH} 6.0)$ in a microwave oven $\left(95-100^{\circ} \mathrm{C}\right)$ 2 times for $10 \mathrm{~min}$ each. Endogenous peroxidase activity was blocked using 3\% hydrogen peroxide. After an additional blocking with $10 \%$ normal goat serum, the sections were incubated with an anti-SLP-2 rabbit polyclonal antibody (1:300 dilution; Proteintech Group, Inc., Chicago, IL, USA) in $0.1 \% \mathrm{BSA} / \mathrm{PBS}$ at $4^{\circ} \mathrm{C}$ overnight, followed by incubation with a biotinylated anti-rabbit secondary antibody (Long Island Biotec., Shanghai, China) at $37^{\circ} \mathrm{C}$ for $15 \mathrm{~min}$. The signal was detected using a DAB kit (Maixin Bio., Fuzhou, Fujian, China). Finally, the sections were counterstained with hematoxylin solution. SLP-2-positive cells were counted and photographed under a light microscope. The negative control was conducted by replacing the primary antibody with $0.1 \%$ BSA/PBS.

SLP-2 expression was scored using an immunoreactive scoring scale and evaluated by 2 independent pathologists without any prior knowledge of the patient clinical information. The proportion of positive cells was scored by the extent of immunostaining and was assigned to one of the following categories: 0 ( $0 \%$, no positive cells), 1 ( $\leq 25 \%$ positive cells), 2 (26-50\% positive cells), 3 (51-75\% positive cells) and 4 ( $>75 \%$ positive cells). The intensity of immunostaining was scored as 0 (no staining), 1 (weak staining), 2 (moderate staining) and 3 (strong staining). A final immunoreactive score, also known as the staining index (SI), was determined by the sum of the positive extent and staining intensity. SI was clustered into 4 groups: '-', $\leq 2$ sum points; '+', 3-4 sum points; '++', 5-6 sum points and ' +++ ', 7 sum points. For the present study, we defined the cases with grades equal to ' ++ ' and ' +++ ' as having a high level of SLP-2 expression, whereas '-' and ' + ' denoted negative or a low level of SLP-2 expression. The Ki-67 (Santa Cruz Biotechnology, Inc., Santa Cruz, CA, USA) index was expressed as the percentage of positive cells and was used to define distinct nuclear staining. At least 2,000 cells/case were analyzed. Ki-67 expression was classified as high at $\geq 3.0 \%$ and low at $<3.0 \%$.

RNA extraction and quantitative real-time PCR. Total RNA was extracted from the thyroid tissue using TRIzol reagent (Invitrogen Life Technologies, New York, NY, USA), 
according to the manufacturer's instructions. One microgram of total RNA was reversely transcribed using a reverse transcription kit (Takara Bio, Inc., Dalian, Liaoning, China). The specific gene was amplified using PCR. The primer sequences were 5'-GTGACTCTCGACAATGTAAC-3' (forward) and 5'-TGATCTCATAACGGAGGCAG-3' (reverse) for SLP-2; and 5'-ATGGGGAAGGTGAAGGTCGGAGTC-3' (forward) and 5'-GCTGATGATCTTGAGGCTGTTGTC-3' (reverse) for GAPDH (synthesized by Sangon Biotech Co., Ltd., Shanghai, China). PCR amplification was performed at $94^{\circ} \mathrm{C}$ for $30 \mathrm{sec}, 61^{\circ} \mathrm{C}$ for $20 \mathrm{sec}$ and $72^{\circ} \mathrm{C}$ for $30 \mathrm{sec}$ for $40 \mathrm{cycles}$ using the SYBR-Green kit (Takara Bio, Inc.). An initial step of denaturing RNA at $95^{\circ} \mathrm{C}$ for $2 \mathrm{~min}$ and a final extension step at $72^{\circ} \mathrm{C}$ for $5 \mathrm{~min}$ were also performed. Assays were conducted in triplicate and repeated 3 times. The amount of the target (SLP-2) was normalized to an endogenous control (GAPDH) given by $2^{-\Delta \Delta \mathrm{Ct}}$, in which the threshold cycle $\left(\mathrm{C}_{\mathrm{t}}\right)$ was obtained using the sequence detection software v1.4 (7300 Real-Time PCR System; Applied Biosystems, Foster City, CA, USA).

Cell culture and TGF- $\beta 1$ treatment. The human papillary thyroid carcinoma K1 cell line was originally obtained from Sigma (St. Louis, MO, USA) and was a kind gift from Dr G.B. Yuan (Chongqing Medical University, Chongqing, China). K1 cells were cultured in DMEM/Ham's F12/MCDB medium (2:1:1; HyClone, Logan, UT, USA and Sigma) supplemented with $100 \mathrm{IU} / \mathrm{ml}$ penicillin and $100 \mu \mathrm{g} / \mathrm{ml}$ streptomycin in the presence of $10 \%$ fetal bovine serum (Invitrogen Life Technologies, Carlsbad, CA, USA) at $37^{\circ} \mathrm{C}$ in a humidified atmosphere of $5 \% \mathrm{CO}_{2}$. After $24 \mathrm{~h}$, cells were treated with $10 \mathrm{ng} / \mathrm{ml}$ of recombinant human TGF- $\beta 1$ (R\&D Systems, Minneapolis, MN, USA) in complete medium for 0, 24, 48 and $72 \mathrm{~h}$.

Western blotting. Equal amounts of proteins were separated by SDS-PAGE and transferred to PVDF membranes. After blocking with $1 \%$ skim milk in TBS-T at room temperature for $1 \mathrm{~h}$, the membranes were probed with rabbit anti-rat SLP-2 or $\beta$-actin (1:7,000 dilution each; Proteintech Group) and Smad2 or phospho-Smad2 (1:500 dilution each; Cell Signaling Technology, Inc., Beverly, MA, USA) primary antibodies, respectively, at $4^{\circ} \mathrm{C}$ overnight and subsequently incubated with horseradish peroxidase-conjugated goat anti-rabbit secondary antibody (1:8,000 dilution; Proteintech Group) at room temperature for $1 \mathrm{~h}$. Signals were detected using Pierce SuperSignal West Femto Maximum Sensitivity Substrate (Thermo Fisher Scientific Inc., Rockford, IL, USA) and quantified using Tanon-4500 gel imaging system with GIS ID analysis software v4.1.5 (Tanon Science \& Technology Co., Ltd., Shanghai, China).

Statistical analysis. All analyses were performed with SPSS version 13.0 for Windows (SPSS, Inc., Chicago, IL, USA). For correlation between SLP-2 expression and histological types or the clinicopathological characteristics, the Chi-square test or the Fisher's exact test was performed as indicated. For comparison between 2 groups and multi-groups, a Student's t-test and ANOVA were used, respectively. A significant difference was considered at a value of $\mathrm{P}<0.05$.
Table I. SLP-2 expression in the PTC cases.

\begin{tabular}{|c|c|c|c|}
\hline & Tumor $\mathrm{n}(\%)$ & Normal n (\%) & P-value \\
\hline Total PTC & & & $<0.001^{\mathrm{a}}$ \\
\hline Patients (n) & $107(100.00)$ & $107(100.00)$ & \\
\hline High & 77 (71.96) & 15 (14.02) & \\
\hline Low & $30 \quad(28.04)$ & $92 \quad(85.98)$ & \\
\hline Classical & & & $<0.001^{\mathrm{a}}$ \\
\hline Patients (n) & $99(100.00)$ & $99(100.00)$ & \\
\hline High & $71 \quad(71.72)$ & 13 (13.13) & \\
\hline Low & $28 \quad(28.28)$ & $86 \quad(86.87)$ & \\
\hline Follicular variant & & & $0.066^{\mathrm{b}}$ \\
\hline Patients (n) & $8(100.00)$ & $8(100.00)$ & \\
\hline High & $6 \quad(75.00)$ & $2(25.00)$ & \\
\hline Low & $2(25.00)$ & $6 \quad(75.00)$ & \\
\hline
\end{tabular}

For statistical analysis, ${ }^{\mathrm{a}} \chi^{2}$ test and ${ }^{\mathrm{b}}$ Fisher's exact test were applied in total PTC and classical PTC, and follicular variant PTC cases, respectively. $n$, number of cases. Bold value indicates a significant difference (tumor vs. normal tissue). High, high level of SLP-2 expression; Low, low level of SLP-2 expression. SLP-2, stomatinlike protein 2; PTC, papillary thyroid cancer.

\section{Results}

Overexpression of SLP-2 in human PTC. We observed that the classical PTC cases manifested papillary formation with nuclear characteristics. The 99 classical PTC cases displayed the principal microscopic features of papillary architecture and nuclear features, such as irregularity of nuclear contours, nuclear pseudo-inclusions, enlargement, crowding, overlapping and grooves; whereas the cases of the follicular variants of PTC comprising $8.08 \%$ (8/107) of the total PTC cases were defined based on diagnostic criteria as having complete lack of well-developed papillae, but exhibited the presence of an exclusively or predominantly follicular growth pattern with characteristic nuclear features of papillary carcinoma. Immunohistochemical staining analysis indicated the heterogeneous positivity of SLP-2 expression in PTC tissues. SLP-2 expression was mainly present in the cytoplasm with minor expression in the plasma membrane of PTC cells with different scores of staining index. A negative staining of SLP-2 was observed in the adjacent normal tissues to the primary tumors (Fig. 1A and B). However, a few cases of positive staining were also noted in the adjacent normal tissues. Using the SI system, the level of SLP-2 expression in the tissues was classified as high and low. We found that a high level of SLP-2 expression was more frequent in the tumor tissues when compared with that in the adjacent normal tissues to the primary tumors (Table I; $\mathrm{P}<0.001$ ), particularly in the classical PTC cases (Fig. 1C-H); whereas a negative or low level of SLP-2 expression was observed more frequently in the adjacent normal tissues when compared with that in the tumor tissues. In the follicular variant cases, however, there was no significant difference in SLP-2 expression between the tumor tissues and adjacent normal tissues $(P>0.05)$. Since the 

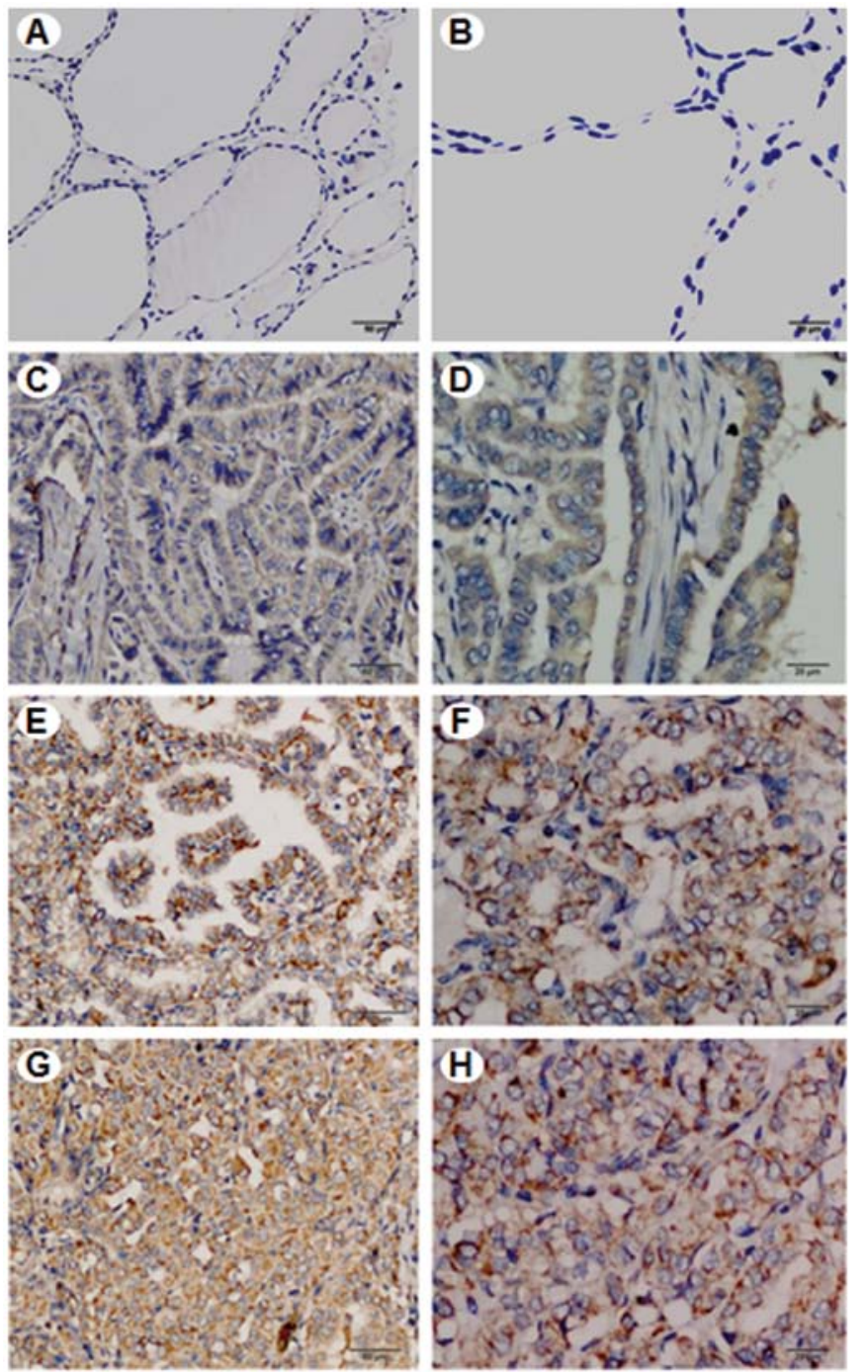

Figure 1. SLP-2 expression in human classical PTC. Immunohistochemica staining analysis shows the heterogeneous positivity of SLP-2 expression with the 4 different scores. Histologically non-tumor tissue, adjacent normal tissue to the primary tumor, was used as a control and showed negative staining (A and B). Heterogeneous positivity of SLP-2 expression was found in PTC tissues $(\mathrm{C}-\mathrm{H})$. A brown color shown in the cytoplasm was considered as positive staining. Representative images are shown. (A and B) Score of (-), negative staining. (C and D) Score of (+), weak staining. (E and F) Score of $(++)$, moderate staining. ( $\mathrm{G}$ and $\mathrm{H})$ Score of $(+++)$, strong staining. All sections were counterstained with hematoxylin. (A,C,E,G) Original magnification, $\mathrm{x} 200$ (scale bar, $50 \mathrm{~mm}$ ). (B,D,F,H) Original magnification, $\mathrm{x} 400$ (scale bar, $20 \mathrm{~mm}$ ). SLP-2, stomatin-like protein 2; PTC, papillary thyroid cancer.

sample number was quite small (8 cases of follicular variant), we could not make a conclusion at this point that SLP-2 is an indicator for the diagnosis of classical PTC.

Association of SLP-2 expression with the clinicopathological characteristics of PTC. In order to examine the correlation between SLP-2 expression and the clinicopathological features, we classified the cases according to high and low SLP-2 expression. The clinical information of patients was obtained from their charts and is documented in Table II. We grouped patients according to age at the time of diagnosis $(<45$ years, young patients and $\geq 45$ years, older patients), gender (female and male), primary tumor size $(<1 \mathrm{~cm}$ and $\geq 1 \mathrm{~cm})$, presence of
Table II. Correlation of the clinicopathological features of the patients with PTC subgrouped according to low or high expression of SLP-2 as determined by immunohistochemistry.

\begin{tabular}{|c|c|c|c|c|}
\hline \multirow{2}{*}{$\begin{array}{l}\text { Clinicopathological } \\
\text { features }\end{array}$} & \multirow[b]{2}{*}{$\mathrm{n}$} & \multicolumn{2}{|c|}{ SLP-2 expression } & \multirow[b]{2}{*}{ P-value } \\
\hline & & Low n $(\%)$ & High n (\%) & \\
\hline Total patients & 107 & & & \\
\hline $\begin{array}{l}\text { Age (years) } \\
\text { at diagnosis }\end{array}$ & & & & 0.543 \\
\hline$<45$ & 44 & $15(34.09)$ & $29(65.91)$ & \\
\hline$\geq 45$ & 63 & $18(28.57)$ & $45(71.43)$ & \\
\hline Gender & 107 & & & 0.949 \\
\hline Female & 72 & $21(29.17)$ & $51(70.83)$ & \\
\hline Male & 35 & $10(28.57)$ & $25(71.43)$ & \\
\hline Primary tumor size & 107 & & & $<0.001$ \\
\hline$<1 \mathrm{~cm}$ & 45 & $27(60.00)$ & $18(40.00)$ & \\
\hline$\geq 1 \mathrm{~cm}$ & 62 & $4(6.45)$ & $58(93.55)$ & \\
\hline Multifocal tumors & 107 & & & 0.153 \\
\hline Yes & 18 & $3(16.67)$ & $15(83.33)$ & \\
\hline No & 89 & $30(33.71)$ & $59(66.29)$ & \\
\hline LN involvement & 99 & & & $<0.001$ \\
\hline Yes & 42 & $4 \quad(9.52)$ & $38(90.48)$ & \\
\hline No & 57 & $25(43.86)$ & $32(56.14)$ & \\
\hline Tumor stage & 107 & & & 0.001 \\
\hline $\mathrm{T} 1$ & 70 & $29(41.43)$ & $41 \quad(58.57)$ & \\
\hline $\mathrm{T} 2$ & 16 & $0 \quad(0.00)$ & $16(100.00)$ & \\
\hline $\mathrm{T} 3$ & 12 & $2(16.67)$ & $10 \quad(83.33)$ & \\
\hline $\mathrm{T} 4$ & 9 & $\begin{array}{ll}0 & (0.00)\end{array}$ & $9(100.00)$ & \\
\hline Histological type & 107 & & & 0.602 \\
\hline Classical & 99 & $28(28.28)$ & $71(71.72)$ & \\
\hline Follicular variant & 8 & $2(25.00)$ & $6(75.00)$ & \\
\hline Ki-67 expression & 86 & & & 0.043 \\
\hline$\geq 3.0 \%$ & 21 & $2(9.52)$ & $19(90.48)$ & \\
\hline$<3.0 \%$ & 65 & $20(30.77)$ & 45 (69.23) & \\
\hline
\end{tabular}

Correlation of SLP-2 protein expression with age, gender, tumor size, multifocal tumors, lymph node invasion, clinical stage, histological type and Ki-67 expression. Low, low level of SLP-2 expression; High, high level of SLP-2 expression; n, number of cases; LN, lymph node; $\mathrm{T}$, tumor grade: T1, tumor $<2 \mathrm{~cm}$; T2, tumor $2-4 \mathrm{~cm}$; $\mathrm{T} 3$, tumor $>4 \mathrm{~cm}$; $\mathrm{T} 4$, tumor extension beyond the thyroid capsule. Bold value indicates a significant difference between each parameter. $\mathrm{T} 1$ vs. $\mathrm{T} 2, \mathrm{P}=0.001^{\mathrm{a}} ; \mathrm{T} 1$ vs. $\mathrm{T} 3, \mathrm{P}=0.091^{\mathrm{a}} ; \mathrm{T} 1$ vs. $\mathrm{T} 4, \mathrm{P}=0.012^{\mathrm{a}} ; \mathrm{T} 2$ vs. $\mathrm{T} 3, \mathrm{P}=0.175^{\text {b}}$; $\mathrm{T} 2$ vs. T4, not applicable due to $100 \%$ expression of SLP-2 in both stages; T3 vs. T4, P=0.314 ${ }^{\mathrm{b}} .{ }^{\mathrm{a}} \chi^{2}$ test; ${ }^{\mathrm{b}}$ Fisher's exact test. SLP-2, stomatin-like protein 2.

multifocal tumors, lymph node involvement and tumor stage. By comparing SLP-2 expression with the clinicopathological parameters, we found that there was no difference in SLP-2 expression between the young and older patients. Although PTC patients were predominantly female (72 vs. 35 male cases), the overall expression level of SLP-2 was not different 

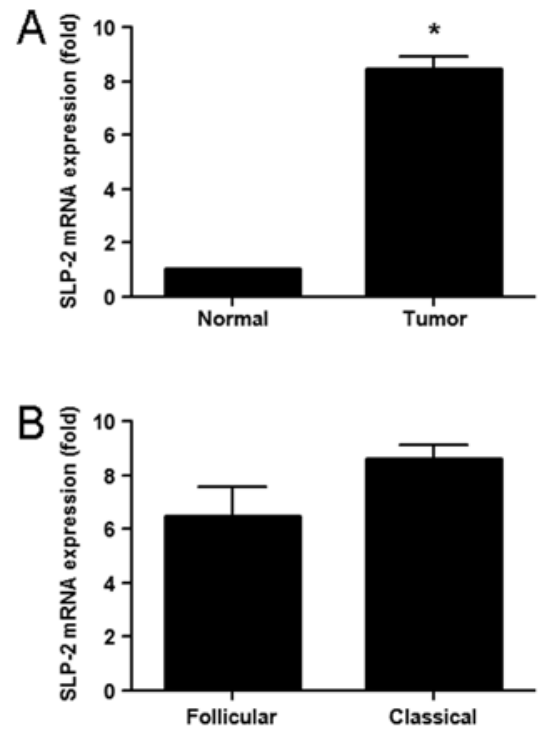

Figure 2. Expression of SLP-2 mRNA in PTC. Total RNA was extracted from freshly isolated primary tumor and adjacent normal tissues. The expression of SLP-2 mRNA was determined by real-time qPCR. (A) Comparison of mRNA expression of SLP-2 in 33 normal tissues and 42 PTC tissues. The expression level of SLP-2 mRNA was 8-fold higher in the primary tumor tissue than that in the normal tissue. "P<0.05. (B) Comparison of the expression of SLP-2 mRNA in classical PTC and follicular variant PTC (39 vs. 3 ) cases. Quantitative analysis showed no difference in SLP-2 mRNA expression between classical PTC and follicular variant of PTC. SLP-2, stomatin-like protein 2; PTC, papillary thyroid cancer.

between female and male cases, and was not correlated with multifocal tumors. Among the 107 cases, however, SLP-2 expression was strongly correlated with primary tumor size (Table II; $\mathrm{P}<0.001$ ). In the group of tumors with size $\geq 1 \mathrm{~cm}$, the cases having a high level of SLP-2 expression reached $93.55 \%$. Importantly, there was a significant association between SLP-2 expression and lymph node metastasis and tumor stage ( $\mathrm{P} \leq 0.001$, respectively). A high level of SLP-2 expression was detected in $90.48 \%$ of metastatic lymph nodes close to the tumor. The expression of SLP-2 in T1 cases (tumor $<2 \mathrm{~cm}$ ) was significantly different than its expression in other stages; there were no obvious differences in SLP-2 expression among T2 (tumor 2-4 cm), T3 (tumor $>4 \mathrm{~cm}$ limited to the thyroid) and $\mathrm{T} 4$ cases (tumor extension beyond the thyroid capsule). These data indicate that SLP-2 overexpression may be correlated with disease progression.

Next, we examined whether the expression level of SLP-2 is altered at the mRNA level and ascertained whether the expression pattern is correlated with the clinicopathological features of patients with PTC. Total RNA was extracted from freshly isolated tumors (39 classical PTCs and 3 follicular variants) and adjacent normal tissues (33 cases) and was subjected to qPCR. We found that the expression of SLP-2 mRNA was 8 -fold higher in the primary tumor tissues than that in the normal tissue (Fig. 2A; P<0.05). Quantitative analysis showed no difference in SLP-2 mRNA expression between classical PTC cases and the follicular variant PTC cases (Table III; Fig. 2B). Following comparison with clinicopathological features, we found that there was no significant difference in SLP-2 mRNA in regards to age ( $<45$ vs. $\geq 45$ years), gender (female vs. male), primary tumor size $(<1 \mathrm{~cm}$ vs. $\geq 1 \mathrm{~cm})$ and
Table III. Correlation between expression of SLP-2 mRNA and the clinicopathological features of the PTC cases.

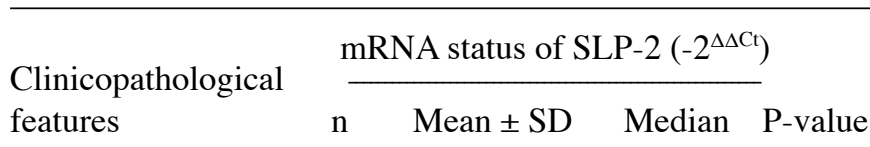

Age (years)

$0.102^{\mathrm{a}}$

at diagnosis

$\begin{array}{llll}<45 & 22 & 9.458 \pm 0.846 & 7.623 \\ \geq 45 & 20 & 7.507 \pm 0.543 & 7.016\end{array}$

Gender

Female

Male

$26 \quad 8.414 \pm 0.688 \quad 7.311$

$\begin{array}{lll}16 & 8.471 \pm 0.763 \quad 7.597\end{array}$

Primary tumor size

$<1 \mathrm{~cm}$

$\geq 1 \mathrm{~cm}$

$20 \quad 7.430 \pm 0.545$

6.941

$22 \quad 9.350 \pm 0.801 \quad 8.762$

Multifocal tumors

Yes

No

$6 \quad 7.961 \pm 1.716$

6.527

$\begin{array}{lll}36 & 8.515 \pm 0.533 \quad 7.438\end{array}$

$\mathrm{LN}$ involvement

Yes

No

$17 \quad 10.370 \pm 0.868$

9.714

$20 \quad 7.002 \pm 0.577$

6.639

Tumor stage

$\mathrm{T} 1$

$\mathrm{T} 2$

T3

T4

$26 \quad 7.588 \pm 0.541 \quad 6.941$

$\begin{array}{lll}6 & 6.958 \pm 0.813 \quad 6.722\end{array}$

$6 \quad 11.490 \pm 1.180 \quad 11.440$

$\begin{array}{lll}4 & 11.590 \pm 2.394 & 11.260\end{array}$

Histological type

Classical

Follicular variant

$398.585 \pm 0.538$

7.413

$3 \quad 6.495 \pm 1.063$

6.364

$0.272^{\mathrm{a}}$

Ki-67 expression

$\geq 3.0 \%$

$8 \quad 12.040 \pm 1.511 \quad 12.210$

$<3.0 \%$

$33 \quad 7.583 \pm 0.426$

7.013

Correlation of SLP-2 mRNA expression and age, gender, tumor size, multifocal tumors, lymph node invasion, histological type and Ki-67 expression. $\mathrm{n}$, number of cases; $\mathrm{SD}$, standard deviation; $\mathrm{LN}$, lymph node; $\mathrm{T}$, tumor grade: $\mathrm{T} 1$, tumor $<2 \mathrm{~cm}$; $\mathrm{T} 2$, tumor $2-4 \mathrm{~cm}$; T3, tumor $>4 \mathrm{~cm}$; T4, tumor extension beyond the thyroid capsule. Bold value indicates a significant difference (tumor vs. normal tissue). T1 vs. T2, $\mathrm{P}=0.603 ; \mathrm{T} 1$ vs. T3, $\mathrm{P}=0.004 ; \mathrm{T} 1$ vs. T4, $\mathrm{P}=0.021 ; \mathrm{T} 2$ vs. $\mathrm{T} 3, \mathrm{P}=0.010$; $\mathrm{T} 2$ vs. T4, $\mathrm{P}=0.063$; T3 vs. T4, $\mathrm{P}=0.969$. ${ }^{\mathrm{a}}$ Two group comparison by Student's t-test; 'one-way ANOVA. SLP-2, stomatin-like protein 2.

the presence of multifocal tumors (Table III). However, SLP-2 overexpression was significantly correlated with lymph node metastasis and tumor stage $(\mathrm{P}<0.005$, respectively). These data were in agreement with the IHC observation that SLP-2 may be considered as a potential biomarker for human PTC.

Correlation of SLP-2 expression with the proliferation index $\mathrm{Ki}-67 . \mathrm{Ki}-67$ is a nuclear protein and is highly expressed in proliferating cells. Thus, it is a proliferation marker and has been showed to be well correlated with tumor stage and the 
A

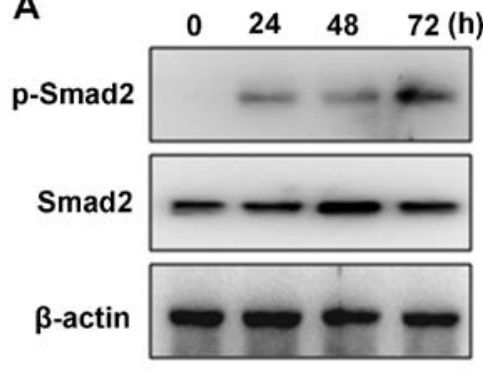

B
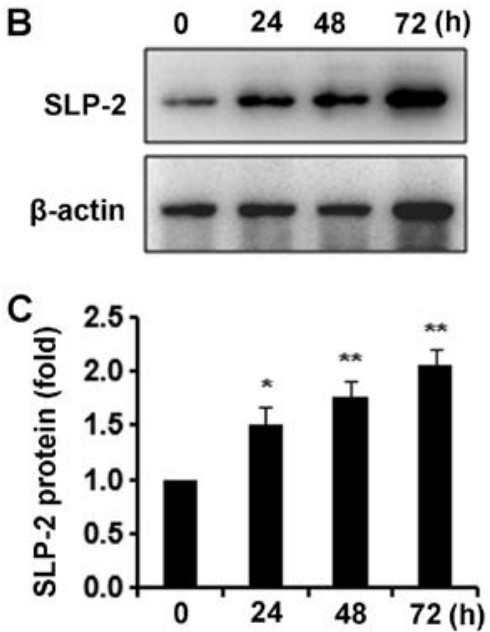

Figure 3. Effect of TGF- $\beta 1$ on SLP-2 protein expression in K1 cells. Tota protein was extracted from thyroid cancer K1 cells following stimulation with or without $10 \mathrm{ng} / \mathrm{ml} \mathrm{TGF}-\beta 1$ for $0,24,48$ and $72 \mathrm{~h}$ and was separated on SDSPAGE. SLP-2 protein was detected by western blotting. (A) Representative images of phospho-Smad2 and total Smad2 are shown $(n=2)$. $\beta$-actin was used as a loading control. (B) SLP-2 was detected by western blotting. (C) Histogram shows the quantitative analysis of the gel after densitometry. The expression of SLP-2 was normalized to $\beta$-actin $(n=3)$. ${ }^{*} \mathrm{P}<0.05$ when compared with the control group. TGF- $\beta 1$, transforming growth factor- $\beta 1$; SLP-2, stomatin-like protein 2.

clinical outcome of PTC (24). However, the positive rate of $\mathrm{Ki}-67$ is low in differentiated PTC and thus, Ki-67 is difficult to be used as a diagnostic marker alone. In the present study, we found that a high level of SLP-2 protein expression was positively correlated with Ki-67 expression in PTC (Table II). There was a significant increase in the expression of SLP-2 protein observed in the high $\mathrm{Ki}$-67-expressing group, when compared with the low Ki-67-expressing group $(\mathrm{P}<0.05)$. In addition, expression of SLP-2 mRNA was also higher in the high Ki-67-expressing group than that in the low Ki-67expressing group (Table III; $\mathrm{P}<0.01$ ).

Regulation of SLP- 2 expression by TGF- $\beta 1$. Since TGF- $\beta$ is expressed in differentiated thyroid cancer and plays a crucial role in thyroid tumorigenesis (25), we subsequently examined whether TGF- $\beta$ is involved in the regulation of SLP-2 expression. The effect of TGF- $\beta 1$ on SLP-2 expression was assessed in human PTC K1 cells. First, we found that $\mathrm{K} 1$ cells were responsive to TGF- $\beta 1$ as an increase in the phosphorylation of $\mathrm{Smad} 2$, a downstream signaling protein of TGF- $\beta 1$, was detected by western blotting after $10 \mathrm{ng} / \mathrm{ml}$ of TGF- $\beta 1$ treatment (Fig. 3A). Next, we observed an increase in SLP-2-expression after TGF- $\beta 1$ stimulation in a time-course study (Fig. 3B). Densitometric analysis showed that TGF- $\beta 1$ significantly upregulated the expression of SLP-2 protein at 24, 48 and 72 h (Fig. 3C).

\section{Discussion}

The present study showed for the first time that SLP-2 is overexpressed in human PTC and is associated with its clinicopathological features. SLP-2 is a novel member of the stomatin superfamily that shares the cognate stomatin signature sequence. However, SLP-2 is unique and is distinguished from stomatin, SLP-1 and SLP-3 by the absence of an NH2-terminal hydrophobic domain (7). Since 2006, it has been determined that SLP-2 is overexpressed in several undifferentiated human carcinomas, including ESCC, LSCC and endometrial adenocarcinoma. Here, we identified SPL-2 overexpression in a differentiated cancer, human PTC.

In the present study, when compared with the adjacent normal tissue, the overexpression of SLP-2 in the primary tumors of PTC was found to be mainly located in the cytoplasm with some distribution on the membrane as detected by IHC; these findings were in agreement with its distribution in human endometrial adenocarcinoma (26). A recent study suggests that there may be a net exchange of membrane material between mitochondria and plasma membrane (8). However, the function of SLP-2 in human PTC is unknown. It has been showed that SLP-2 is upregulated under conditions of mitochondrial stress and interacts with prohibitins, chaperones in respiratory chain complexes, in the mitochondrial inner membrane (13). SLP-2 is required for stress-induced mitochondrial hyperfusion (SIMH) (11). Upregulation of SLP-2 expression increases the mitochondrial membrane phospholipid cardiolipin content and binds to cardiolipin to induce mitochondrial biogenesis (12). Moreover, SLP-2 deficiency is associated with impaired cardiolipin compartmentalization in mitochondrial membranes (27). It has also been shown that SLP-2 negatively modulates mitochondrial sodium-calcium exchange (28). These data indicate that SLP-2 plays a role in regulating mitochondrial membrane stability and function.

Based on clinical analysis, the present study demonstrated that there was no significant difference in SLP-2 expression in regards to gender and age. It has been shown that the overall outcome of women with PTC is similar to men, although subgroup analysis showed that the first age period ( $<55$ years) is a period with better outcomes for women than men and the second period ( $\geq 55$ years) is a period with similar outcomes for both women and men (29). These data suggest that SLP-2 expression is not correlated with gender and age at the time of diagnosis.

Tumorigenesis is complex and involves multistage processes. IHC analysis from the present study showed that high expression of SLP-2 was correlated with tumor size rather than multifocal involvement. Furthermore, our data revealed expression of SLP-2 in the cytoplasm of PTC cells that was not associated with histological type, but significantly associated with tumor stage, which was confirmed by qPCR after analyzing 42 cases of PTC. The highest expression was found in stage T4 (tumor extension beyond the thyroid capsule) tumors, which is in agreement with a previous study that expression of SLP-2 is associated with invasiveness of 
ESCC (30). SLP-2 alterations occur early in the process of tumor formation, which may predispose to malignant transformation. The present study suggests that SLP-2 represents an important molecular marker that is clinically relevant to the invasion of PTC.

Following further analysis with clinical features, we found that the expression of SLP-2 mRNA and protein was significantly higher in the lymph nodes with metastasis than that in the lymph nodes without metastasis. Such overexpression of SLP-2 was also found in the metastatic lymph nodes of LSCC (16). Previous evidence suggests that high SLP-2 expression contributes to the progression and poor prognosis of gastric cancer (19). SLP-2 may also contribute to the promotion of cell growth and tumorigenesis. The present study showed that SLP-2 was highly associated with $\mathrm{Ki}-67$, a cell proliferation marker, and that the expression of SLP-2 mRNA was positively correlated with tumor stage. These data support a previous report that Ki-67 immunoreactivity is significantly associated with tumor stage and clinical outcome in patients with differentiated thyroid carcinoma (24). Furthermore, downregulation of SLP-2 protein was found to inhibit tumor cell motility and proliferation and enhance cell sensitivity to chemotherapeutic reagents (20). Transfection of SLP-2 antisense resulted in a decrease in cell growth, adhesion and tumorigenesis (14). These data indicate that SLP-2 may be an important player in tumorigenesis, and the detection of SLP-2 expression may help to characterize the prognosis of patients with tumor growth.

The etiology of increased SLP-2 expression in human PTC is unknown. It may be mediated by various cytokines, including TGF- $\beta$ that plays a pivotal role in many types of cancers (31). Several studies have shown that the TGF- $\beta /$ Smad signaling pathway is involved in the epithelial-mesenchymal transformation (EMT), local invasion and node metastasis of PTC $(21,22,32)$. TGF- $\beta$ expression was found to be increased in the cytoplasm at the periphery of PTC (21). Compared with the central regions of primary PTCs, the invasive fronts highly express TGF- $\beta$, T $\beta$ RII and pSmad $2(33,34)$. A correlation between TGF- $\beta$ signaling and EMT was also found in human poorly differentiated thyroid carcinoma (PDTC) (32). Previous studies have shown that there is positive staining of TGF- $\beta$ and pSmad 2 in PDTC, which provides evidence that TGF- $\beta$ is involved in the transition from PTC to PDTC (22), suggesting a role for TGF- $\beta$ in mediating this process. However, whether TGF- $\beta$ regulates SLP-2 in thyroid cancer was not previously explored. The present study provides evidence that TGF- $\beta 1$ upregulates the expression of SLP-2. Although the TGF- $\beta$ mediated SLP-2 expression in tumor cells is not completely understood, our study indicates that SLP-2 induction may require the activation of TGF- $\beta$ signaling in vivo, leading to tumor formation and progression of PTC. Further investigation is needed to identify and understand the molecular mechanisms underlying TGF- $\beta$ signaling pathway-mediated SLP-2 expression.

In conclusion, our findings revealed for the first time that patients with PTC exhibit SLP-2 overexpression which is associated with clinicopathological features. The correlation between SLP-2 expression and proliferation marker Ki-67 may be characteristic of PTC and reflect PTC progression. Furthermore, SLP-2 expression is upregulated by TGF- $\beta 1$ in vitro in PTC cells, indicating a possible role of SLP-2 in PTC tumorigenesis. Thus, SLP-2 may be considered as a valuable biomarker for patients with PTC, and the present study identifies SLP-2 as a potential therapeutic target for the treatment of PTC.

\section{Acknowledgements}

We thank Dr G.B. Yuan (Chongqing Medical University, Chongqing, China) for kindly providing the $\mathrm{K} 1$ cells. The present study was supported by grants from the National Natural Science Foundation of China (81272880), the Shanghai Committee of Science and Technology (124119b1300), and the Shanghai Municipal Health Bureau (2012-186) to G.X.

\section{References}

1. Boone RT, Fan CY and Hanna EY: Well-differentiated carcinoma of the thyroid. Otolaryngol Clin North Am 36: 73-90, 2003.

2. Siegel R, Naishadham D and Jemal A: Cancer statistics, 2013. CA Cancer J Clin 63: 11-30, 2013.

3. Mazzaferri EL and Jhiang SM: Long-term impact of initial surgical and medical therapy on papillary and follicular thyroid cancer. Am J Med 97: 418-428, 1994.

4. Schlumberger MJ: Papillary and follicular thyroid carcinoma. N Engl J Med 338: 297-306, 1998.

5. French JD, Weber ZJ, Fretwell DL, Said S, Klopper JP and Haugen BR: Tumor-associated lymphocytes and increased FoxP $3^{+}$regulatory $\mathrm{T}$ cell frequency correlate with more aggressive papillary thyroid cancer. J Clin Endocrinol Metab 95: 2325-2333, 2010 .

6. Kilicarslan AB, Ogus M, Arici C, Pestereli HE, Cakir M and Karpuzoglu G: Clinical importance of vascular endothelial growth factor (VEGF) for papillary thyroid carcinomas. APMIS 111: 439-443, 2003.

7. Wang Y and Morrow JS: Identification and characterization of human SLP-2, a novel homologue of stomatin (band 7.2b) present in erythrocytes and other tissues. J Biol Chem 275: 8062-8071, 2000.

8. Christie DA, Kirchhof MG, Vardhana S, Dustin ML and Madrenas J: Mitochondrial and plasma membrane pools of stomatin-like protein 2 coalesce at the immunological synapse during T cell activation. PLoS One 7: e37144, 2012.

9. Owczarek CM, Treutlein HR, Portbury KJ, Gulluyan LM, Kola I and Hertzog PJ: A novel member of the STOMATIN/EPB72/mec-2 family, stomatin-like 2 (STOML2), is ubiquitously expressed and localizes to HSA chromosome 9p13.1. Cytogenet Cell Genet 92: 196-203, 2001.

10. Green JB and Young JP: Slipins: ancient origin, duplication and diversification of the stomatin protein family. BMC Evol Biol 8: 44, 2008.

11. Tondera D, Grandemange S, Jourdain A, et al: SLP-2 is required for stress-induced mitochondrial hyperfusion. EMBO J 28: 1589-1600, 2009.

12. Christie DA, Lemke CD, Elias IM, et al: Stomatin-like protein 2 binds cardiolipin and regulates mitochondrial biogenesis and function. Mol Cell Biol 31: 3845-3856, 2011.

13. Da Cruz S, Parone PA, Gonzalo P, et al: SLP-2 interacts with prohibitins in the mitochondrial inner membrane and contributes to their stability. Biochim Biophys Acta 1783: 904-911, 2008.

14. Zhang L, Ding F, Cao W, et al: Stomatin-like protein 2 is overexpressed in cancer and involved in regulating cell growth and cell adhesion in human esophageal squamous cell carcinoma. Clin Cancer Res 12: 1639-1646, 2006.

15. Song L, Liu L, Wu Z, et al: Knockdown of stomatin-like protein 2 (STOML2) reduces the invasive ability of glioma cells through inhibition of the NF-кB/MMP-9 pathway. J Pathol 226: 534-543, 2012.

16. Cao WF, Zhang LY, Liu MB, Tang PZ, Liu ZH and Sun BC: Prognostic significance of stomatin-like protein 2 overexpression in laryngeal squamous cell carcinoma: clinical, histologic, and immunohistochemistry analyses with tissue microarray. Hum Pathol 38: 747-752, 2007. 
17. Cao W, Zhang B, Liu Y, et al: High-level SLP-2 expression and HER-2/neu protein expression are associated with decreased breast cancer patient survival. Am J Clin Pathol 128: 430-436, 2007.

18. Han CL, Chen JS, Chan EC, et al: An informatics-assisted labelfree approach for personalized tissue membrane proteomics: case study on colorectal cancer. Mol Cell Proteomics 10: M110.003087, 2011.

19. Liu D, Zhang L, Shen Z, et al: Increased levels of SLP-2 correlate with poor prognosis in gastric cancer. Gastric Cancer: Jan 31, 2013 (Epub ahead of print).

20. Wang Y, Cao W, Yu Z and Liu Z: Downregulation of a mitochondria associated protein SLP-2 inhibits tumor cell motility, proliferation and enhances cell sensitivity to chemotherapeutic reagents. Cancer Biol Ther 8: 1651-1658, 2009.

21. Eloy C, Santos J, Cameselle-Teijeiro J, Soares P and SobrinhoSimões M: TGF-beta/Smad pathway and $B R A F$ mutation play different roles in circumscribed and infiltrative papillary thyroid carcinoma. Virchows Arch 460: 587-600, 2012.

22. Knauf JA, Sartor MA, Medvedovic M, et al: Progression of BRAF-induced thyroid cancer is associated with epithelialmesenchymal transition requiring concomitant MAP kinase and TGF $\beta$ signaling. Oncogene 30: 3153-3162, 2011.

23. Jasani B, Wyllie FS, Wright PA, Lemoine NR, Williams ED and Wynford-Thomas D: Immunocytochemically detectable TGF- $\beta$ associated with malignancy in thyroid epithelial neoplasia. Growth Factors 2: 149-155, 1990.

24. Müssig K, Wehrmann T, Dittmann H, et al: Expression of the proliferation marker Ki-67 associates with tumor staging and clinical outcome in differentiated thyroid carcinomas. Clin Endocrinol 77: 139-145, 2012.

25. Kimura ET, Kopp P, Zbaeren J, et al: Expression of transforming growth factor $\beta 1, \beta 2$, and $\beta 3$ in multinodular goiters and differentiated thyroid carcinomas: a comparative study. Thyroid 9 : 119-125, 1999.
26. Cui Z, Zhang L, Hua Z, Cao W, Feng W and Liu Z: Stomatin-like protein 2 is overexpressed and related to cell growth in human endometrial adenocarcinoma. Oncol Rep 17: 829-833, 2007.

27. Christie DA, Mitsopoulos P, Blagih J, et al: Stomatin-like protein 2 deficiency in $\mathrm{T}$ cells is associated with altered mitochondrial respiration and defective $\mathrm{CD}^{+}{ }^{+} \mathrm{T}$ cell responses. J Immunol 189: 4349-4360, 2012.

28. Da Cruz S, De Marchi U, Frieden M, Parone PA, Martinou JC and Demaurex N: SLP-2 negatively modulates mitochondrial sodium-calcium exchange. Cell Calcium 47: 11-18, 2010.

29. Jonklaas J, Nogueras-Gonzalez G, Munsell M, et al: The impact of age and gender on papillary thyroid cancer survival. J Clin Endocrinol Metab 97: E878-E887, 2012.

30. Cao W, Zhang B, Ding F, Zhang W, Sun B and Liu Z: Expression of SLP-2 was associated with invasion of esophageal squamous cell carcinoma. PLoS One 8: e63890, 2013.

31. Massagué J: TGF $\beta$ in cancer. Cell 134: 215-230, 2008

32. Montero-Conde C, Martin-Campos JM, Lerma E, et al: Molecular profiling related to poor prognosis in thyroid carcinoma. Combining gene expression data and biological information. Oncogene 27: 1554-1561, 2008.

33. Vasko V, Espinosa AV, Scouten $\mathrm{W}$, et al: Gene expression and functional evidence of epithelial-to-mesenchymal transition in papillary thyroid carcinoma invasion. Proc Natl Acad Sci USA 104: 2803-2808, 2007.

34. Riesco-Eizaguirre G, Rodriguez I, De la Vieja A, et al: The $\mathrm{BRAF}^{\mathrm{V} 600 \mathrm{E}}$ oncogene induces transforming growth factor $\beta$ secretion leading to sodium iodide symporter repression and increased malignancy in thyroid cancer. Cancer Res 69: 8317-8325, 2009 